Journal of Advanced Research in Fluid Mechanics and Thermal Sciences

Journal homepage: www.akademiabaru.com/arfmts.html ISSN: 2289-7879

\title{
Effect of Rotation Number on Heat Transfer Characteristics of a Row of Impinging Jets in Confined Channel
}

\author{
Thantup Nontula ${ }^{1}$, Natthaporn Kaewchoothong ${ }^{1}$, Wacharin Kaew-apichai ${ }^{2}$, Chayut Nuntadusit ${ }^{1,3, *}$ \\ Department of Mechanical Engineering, Faculty of Engineering, Prince of Songkla University, Hatyai, Songkhla 90110, Thailand \\ Department of Computer Engineering, Faculty of Engineering, Prince of Songkla University, Hatyai, Songkhla 90110, Thailand \\ 3 Energy Technology Research Center (ETRC), Prince of Songkla University, Hatyai, Songkhla 90110, Thailand
}

\section{ARTICLE INFO ABSTRACT}

Article history:

Received 31 December 2019

Received in revised form 29 August 2020

Accepted 30 August 2020

Available online 6 October 2020

Keywords:

Impinging jets; Rotation number; Heat

transfer; Thermochromic liquid crystals

\begin{abstract}
Jet impingement has been applied for internal cooling in gas turbine blades. In this study, heat transfer characteristics of impinging jets from a row of circular orifices were investigated inside a flow channel with rotations. The Reynolds number (Re) based on the jet mean velocity was fixed at 6,700 . Whereas, the rotation number $(R o)$ of a channel was varied from 0 to 0.0099 . The jet-to-impingement distance ratio $\left(L / D_{j}\right)$ and jet pitch ratio $\left(P / D_{j}\right)$ were respective 2 and $4, D_{j}$ is a jet diameter of $5 \mathrm{~mm}$. The thermochromic liquid crystals (TLCS) technique was used to measure the heat transfer coefficient distributions on an impingement surface. The results show that heat transfer enhancement on a jet impingement surface depended on the effects of crossflow and Coriolis force. The local Nusselt number at $X / D_{j} \leq 20$ on the leading side $(L S)$ was higher than on the trailing side (TS) while heat transfer on the $L S$ at $20 \leq X / D_{j} \leq 40$ gained the lowest, compared to on the TS. The average Nusselt number ratios $\left(\overline{N u}_{R o} / \overline{N u}_{s}\right)$ on the $T S$ at $R o=0.0049$ gave higher than on the $L S$ of around $2.17 \%$. On the other hand, the $\overline{N u}_{R o} / \overline{N u}_{S}$ on the $T S$ at $R o=0.0099$ was less than the $L S$ of about $0.08 \%$.
\end{abstract}

\section{Introduction}

Currently, the trend of the gas turbine industry requires to increase the thermal efficiency of the engine to decrease fuel consumption and environmental impact. One of the methods is increasing the turbine inlet temperature (TIT), which will go up to about $1,700-1,800^{\circ} \mathrm{C}$ in the future. However, the turbine blade still has limited by the melting point temperature of the material. Therefore, it is essential to have effective cooling technology to reduce the damage of the blades. Several cooling technologies in the past have been adopted in a turbine blade to increase heat transfer for both the

\footnotetext{
${ }^{*}$ Corresponding author.

E-mail address: chayut.n@psu.ac.th

https://doi.org/10.37934/arfmts.77.1.161171
} 
internal and external blades, such as pin-fin cooling, rib-serpentine cooling, dimple cooling, film cooling, etc., as shown in Figure 1 [1-8].

Jet impingement is one of several cooling techniques applied in the gas turbine blade. It gives a high cooling rate in the impingement region. Recently, a single modified jet has been investigated for heat transfer enhancement by Kaewchoothong et al., [9], and Nuntadusit et al., [10], who used the air augmented duct to increase the heat transfer rate on an impingement surface at a diameter of air augmented duct ratio $\left(D / d_{j}\right)$ of $2.0,3.3,4.0$, and 6.0 where $d_{j}$ is an inner diameter of jet. They reported that the heat transfer rate for the case of $D / d_{j}=6$ gave the largest by getting $25.42 \%$ higher compared to a conventional impinging jet. Many researchers in the past also studied for multiple impinging jets on a large surface [11-13]. San and Lai [11] studied the effect of jet-to-jet spacing on heat transfer for staggered arrays of impinging jets. They conducted the Reynolds number (Re) of 10,000 to 30,000 and jet-to-jet spacing of 4 to 24 . The crossflow has a strong effect on heat transfer reduction. Then, Esposito [12] investigated heat transfer distributions of impinging jet arrays with two different types, viz., corrugated wall, and extended ports. They concluded that both geometries reduce the crossflow induced degradation on downstream jets while the individual geometries perform better at different Reynolds numbers. Geers et al., [13] evaluated the correlation of heat transfer for hexagonal and in-line arrays of impinging jets at $\operatorname{Re}=5,000$ to 20,000 using thermochromic liquid crystals (TLCs) method. It was found that multiple-jet heat transfer is strongly influenced by jet interactions before and after the impingement.

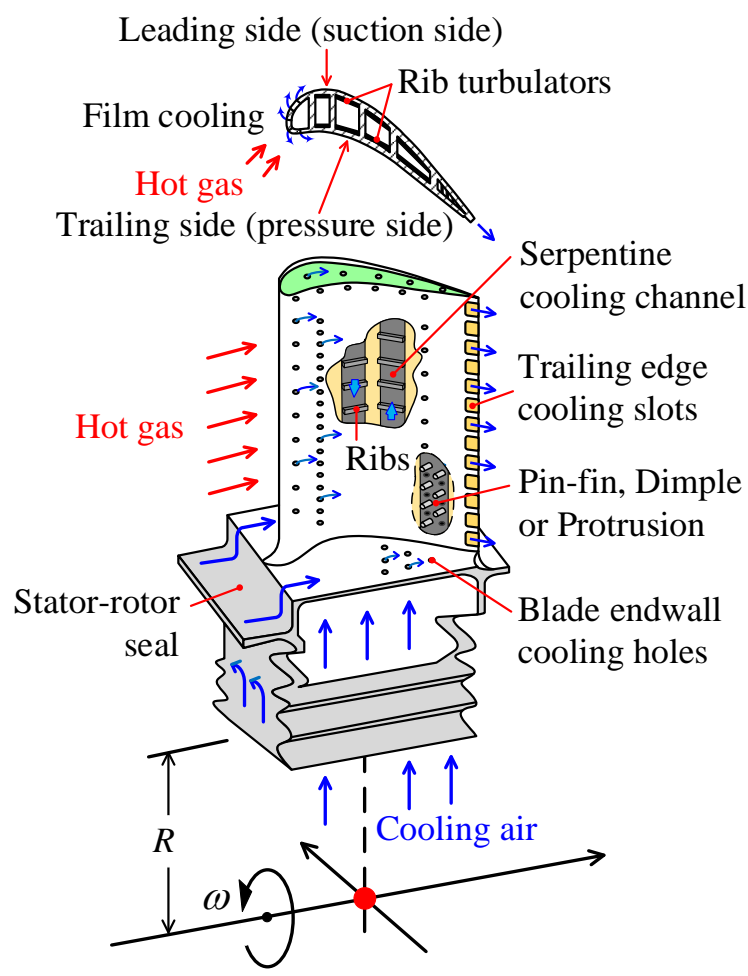

Fig. 1. Cooling technologies of a turbine blade in the past [8]

Additionally, the jet impingement cooling has been adopted in the rotating conditions for the rotor blade, required to remove the heat from the internal blade wall. Elston and Wright [14] studied the effect of rotation on heat transfer characteristics of jet impingement cooling in a channel using the thermocouples. They performed under the jet Reynolds number of 6,000 to 24,000 , and the jet rotation number in the range of 0.0 to 0.13 . They found that the deflection of the impinging jets by 
crossflow combined with the rotation induced secondary flows, increased mixing in the impingement cavity, and enhanced the heat transfer. Parsons et al., [15] investigated the heat transfer of an in-line circular jet array in twin channels under rotations. The jet rotation number varied from $R O=0.0$ to 0.0028 and the Reynolds number varied from 5,000 to 10,000. They concluded that the rotation could increase the heat transfer rate by up to about $15 \%$ when compared to stationary conditions. Recently, the effect of rotation on heat transfer for a single row jet array with crossflow was studied by Lamont et al., [16], who performed at the jet-to-impingement surface distance $\left(L / D_{j}\right)$ of 1,2 , and 3 under the rotational speed of 0 to $275 \mathrm{rpm}$. They found that the heat transfer rate at $L / D_{j}=3$ gave the highest heat transfer for a stationary case while the rotation cases provided the highest heat transfer at $L / D_{j}=2$. Yang et al., [17] studied the influence of rotation on heat transfer in a two-pass channel with impinging jets under $R e$ of 25,000 to 100,000 . It was found that the heat transfer on both sides of the jet impingement increased up to about $25 \%$ due to the Coriolis acceleration effect. Chang and $\mathrm{Yu}$ [18] evaluated the thermal performance of radially rotating trapezoidal channels with impinging jets at $R e=5,000$ to 17,500 and $R o=0.0$ to 0.3 using a thermal infrared camera. They found that The Thermal Performance (TPF) values at $R o=0.0$ were decreased by increasing Re while All the TPF values were increased by increasing $R o$ for all Reynolds numbers.

As mentioned above, although several studies about jet impingement under rotations have been explored, the experimental study still limited to gain the full heat transfer surface for rotating jet impingement. Using the thermochromic liquid crystals (TLCS) method measured in detail to gain the heat transfer coefficient surface was rarely reported. Therefore, the objective of this research aims to study the heat transfer distribution characteristics of impinging jets from a row of circular orifices under rotations. In this study, the thermochromic liquid crystals (TLCs) technique was used to evaluate the heat transfer coefficient on the impingement surface on the leading and trailing side surface. The Reynolds number $(\mathrm{Re})$ and rotation number $(R o)$ based on jet mean velocity were 6,700 and 0.0-0.0099, respectively, while the jet-to-impingement distance ratio was fixed at $L / D_{j}=2$.

\section{Experimental Apparatus and Method}

\subsection{Experimental Model and Its Parameters}

Figure 2 shows the details of a single-row jet impingement channel with a crossflow effect. The impingement channel has $370 \mathrm{~mm}$ length $\left(L_{t}\right)$ and $20 \mathrm{~mm}$ width $(W)$. It has one outlet at the end of the channel, which generates an effect of the crossflow. The number of jet orifices was 13, which was fixed at pitch-to-jet diameter ratio of $P / D_{j}=4$. All of the jet orifices have the same diameter $\left(D_{j}\right)$ of 5 $\mathrm{mm}$. The jet-to-impingement distance ratio was fixed at $L / D_{j}=2$. The heat transfer investigation in this study was considered in the range from the $2^{\text {nd }}$ to $11^{\text {th }}$ orifice jet. For the heat transfer measurement on leading and trailing sides, the rotating direction of the test section was altered clockwise and counter-clockwise as presented in Figure 3. The rotation number was evaluated at $R o$ $=0.0,0.0049$, and 0.0099 , which covers the range of rotating gas turbine engines in the range of $R o$ $=0.0$ to 0.05 for the impinging jet cooling. Besides, the crucial parameters investigated in this research were concluded in Table 1. All experimental measurements have been considered at a constant Reynolds number ( $R e)$ of 6,700 based on the jet mean velocity. 


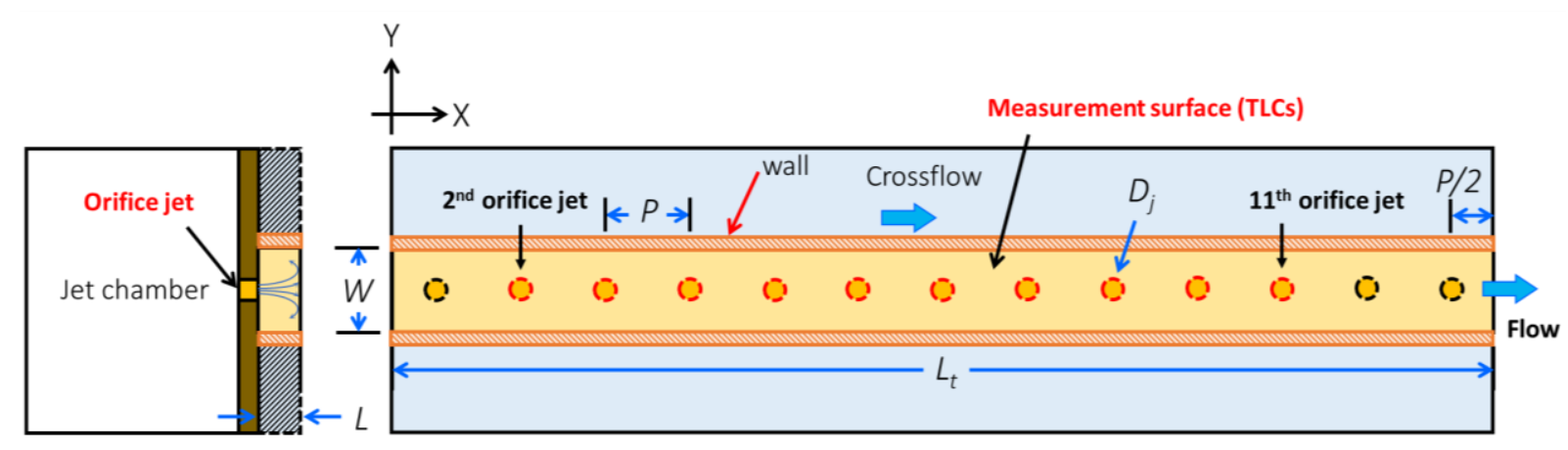

Fig. 2. Single-row jet impingement details used in this study
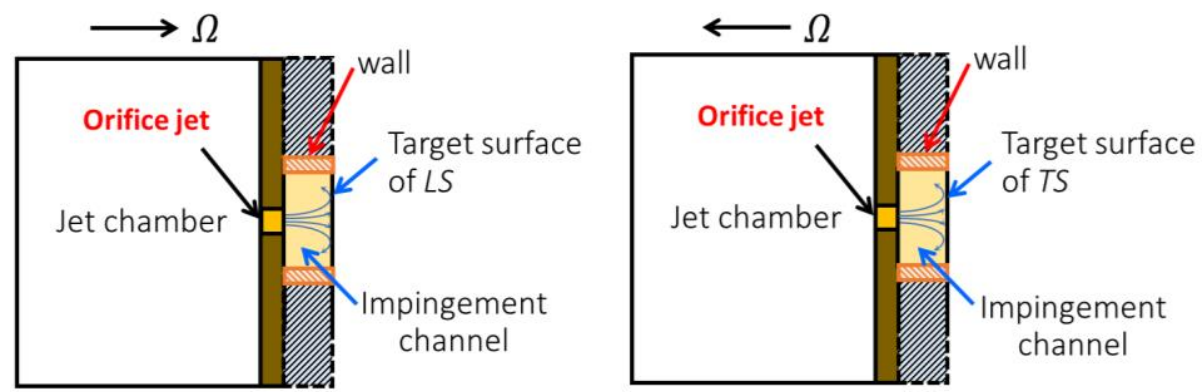

Fig. 3. The direction of a test section evaluated in this work

Table 1

The important parameters for this study

\begin{tabular}{ll}
\hline Parameters and symbol & Values \\
\hline Jet Reynolds number, Re & 6,700 \\
Rotation number, Ro & $0.0,0.0049$, and 0.0099 \\
Number of jets, $n$ & 13 \\
The diameter of a jet, $D_{j}$ & $5.0 \mathrm{~mm}$ \\
Jet-to-impingement surface distance ratio, $L / D_{j}$ & 2 \\
Jet pitch ratio, $P / D_{j}$ & 4 \\
\hline
\end{tabular}

\subsection{Experimental Setup}

The test rig for the impinging jets in the rotating channel was supported by a $1.5 \mathrm{~m} \times 1.5 \mathrm{~m} \times 1.65$ $\mathrm{m}$ steel frame, as shown in Figure 4. It was composed of three crucial parts, viz., the rotating part, the heat flux supplied part, and the air supplied part.

For the rotating part, a test section was placed on one side of a rotating arm and balanced by a counterweight on the opposite side. The rotating arm was installed with a hollow central shaft that had an outside diameter (OD) of $80 \mathrm{~mm}$ and an inner diameter (ID) of $65 \mathrm{~mm}$. The hollow main shaft was held by two bearing supports and one rotary seal. The 2-inch rotary seal was connected with a hollow central shaft for supplied air due to rotations. A $7.46 \mathrm{~kW}$ electric motor controlled by inverter was used to drive the rotating arm via V-belt. The rotation speed of a test section was recorded from a digital encoder.

For the generated and supplied heat flux part, a slip ring that had an OD of $120 \mathrm{~mm}$ and a width of $92 \mathrm{~mm}$ was located on the hollow central shaft. Two contacts of the slip ring were made of copper, which can conduct electric current. Besides, the outer part of a slip ring was contacted with two carbon conductors that connected to the DC power supply to generate constant heat flux on the heat transfer surface in the test section. 
For the air supplied part, a $2.24 \mathrm{~kW}$ blower was controlled by an inverter to adjust the airflow rate, and it was also set to supply air jets into the test section. The air jet temperature was controlled by a temperature controller unit and monitored by a datalogger via thermocouples type $\mathrm{T}$. The orifice flow meter was used to measure the flow rate of air jets.

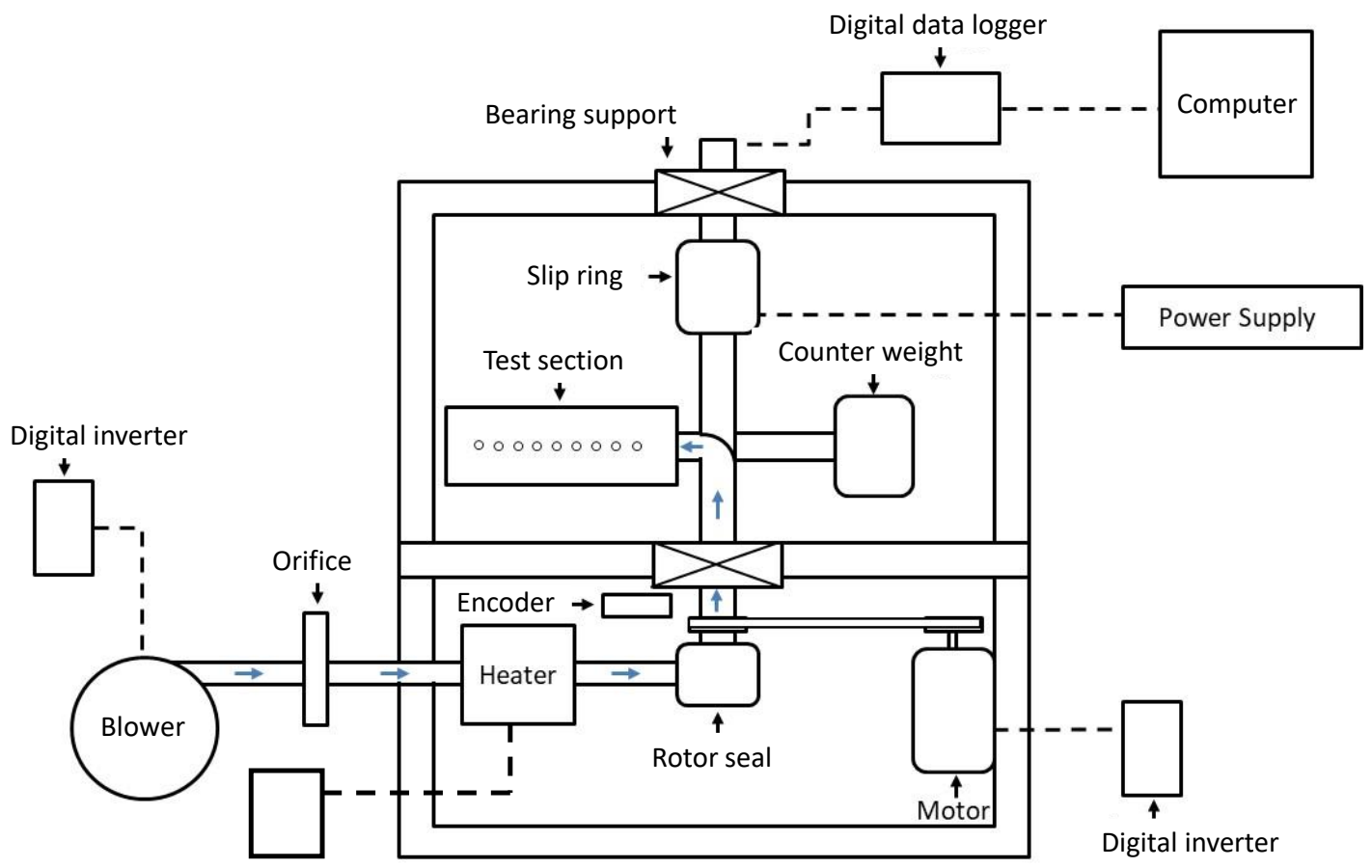

Temperature controller unit

Fig. 4. Experimental setup of the rotating test rig

\subsection{Test Section}

A test section of heat transfer measurement in this study is shown in Figure 5 . It has $370 \mathrm{~mm}$ length $\left(L_{t}\right), 100 \mathrm{~mm}$ width $\left(W_{t}\right)$, and $67 \mathrm{~mm}$ height $\left(H_{t}\right)$. The test section was located at the mean rotating radius-to-jet diameter ratio $\left(R_{m} / D_{j}\right)$ of 67 , which can rotate both clockwise and counterclockwise. In this experiment, the heat transfer surface having a $90 \mathrm{~mm}$ width and a $280 \mathrm{~mm}$ length was made of a stainless foil (SUS304) at $0.03 \mathrm{~mm}$ thick. Stainless foil sheet provides a constant uniform heat flux of about $750 \mathrm{~W} / \mathrm{m}^{2}$ on the heat transfer surface, the electric current at $40 \mathrm{~A}$ from a DC power supply was delivered to the stainless foil sheet through a slip ring and two copper bus bars that were positioned on both ends of the stainless-steel sheet and acrylic plate. The thermochromic liquid crystals (TLCS) sheet attached to the rear side of the heat transfer surface was used to measure the temperature distributions via a CCD camera attached on the test section. The measured range of TLCs temperature was $30-35^{\circ} \mathrm{C}[19,20]$.

Before experiments, the relationship between hue (colour data) and temperature of TLCs on the surface was calibrated to ensure reasonable accuracy, which shown in Figure 6. All data were kept by a digital data logger via a T-type thermocouple, which recorded in incremental steps of about $0.2^{\circ} \mathrm{C}$. When the TLCs colour or temperature on the rear side of the impingement surface reached a steady-state, the TLCs colour pattern was recorded via the CCD camera, which was placed over the test section. Then, the thermal image data on the TLCs sheet was transformed from RGB (Red, Green, and Blue) colour system to hue information. In addition, the image processing method was used to evaluate the temperature and then calculated the heat transfer coefficient. 


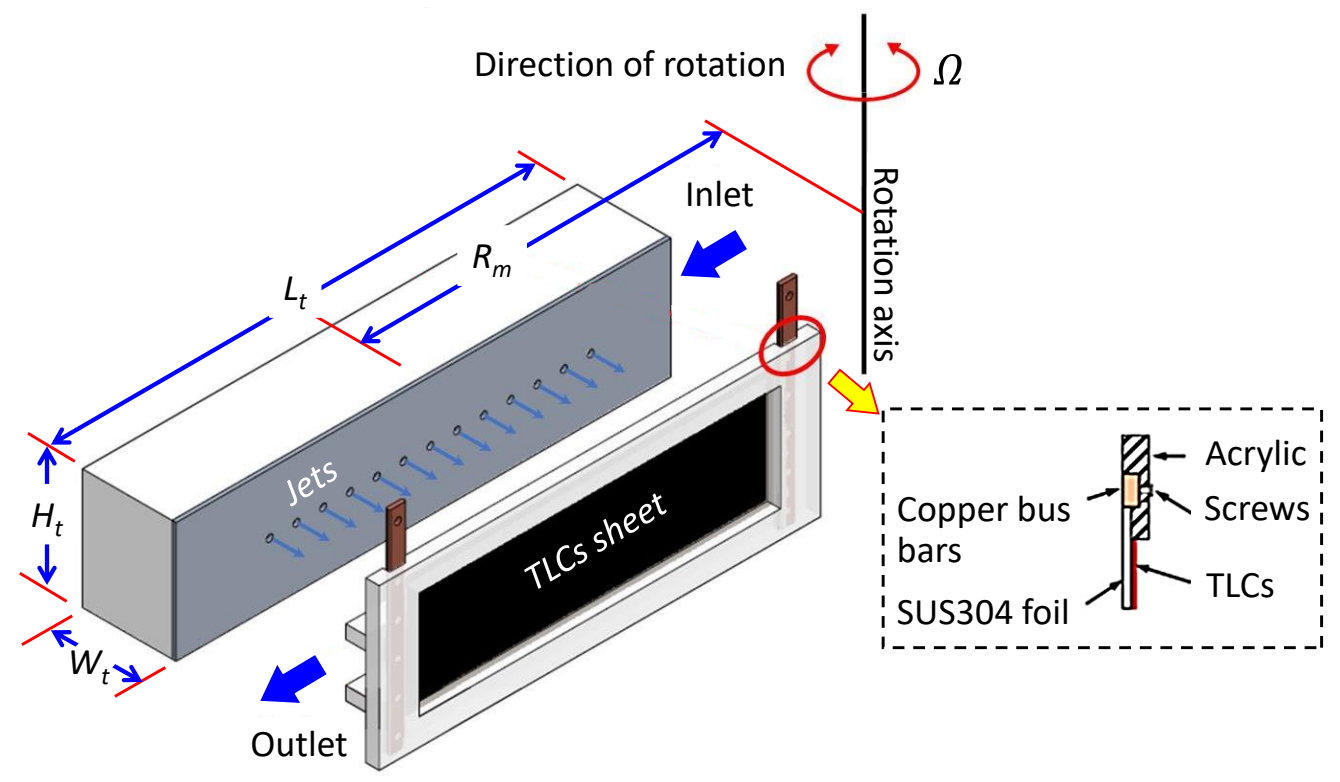

Fig. 5. Details of the test section used for measurement

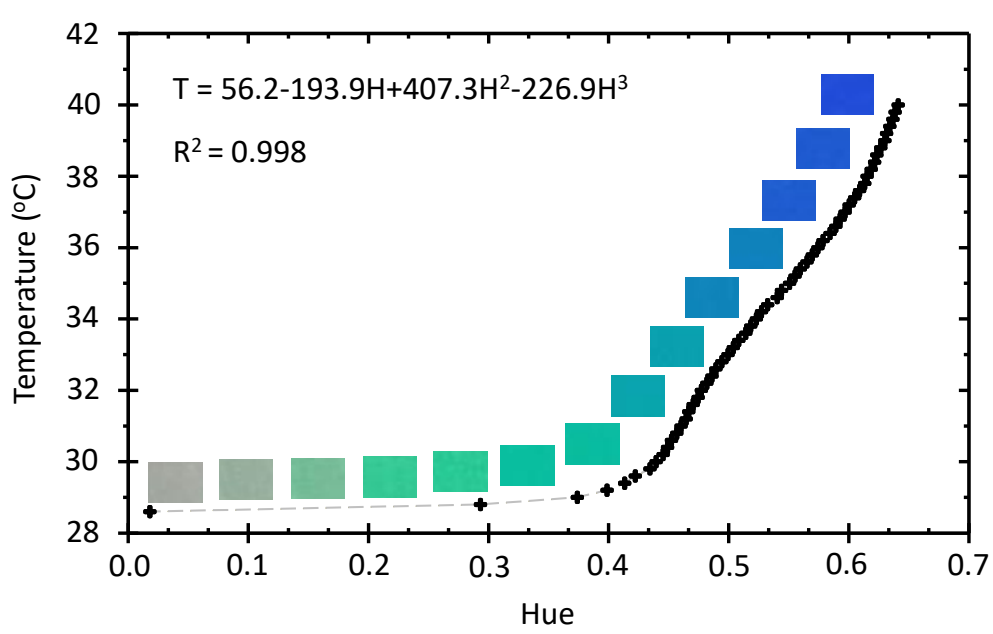

Fig. 6. The calibration curve between hue and temperature values with the developed calibration equation

\section{Data Reduction}

The air was used for working fluid in the experiment. All experimental tests of single-row jet impingement channel under rotations were conducted at the Reynolds number (Re) of 6,700 based on the mean velocity $\left(V_{m}\right)$ of jet flow and the jet diameter $\left(D_{j}\right)$

$R e=\frac{V_{m} D_{j}}{v}$

The rotation speed was normalized in term of rotation number $(R o)$, which can calculate from

$R o=\frac{\Omega D_{j}}{V_{m}}$

where $\Omega$ is the rotating speed of a test section, which is performed at the rotational speed of 0-400 rpm at constant $\operatorname{Re}=6,700$. 
The local heat transfer coefficient $(h)$ on the heat transfer surface can be determined from

$h=\frac{\dot{q}_{n e t}}{\left(T_{w}-T_{m}\right)}$

where $\dot{q}_{n e t}$ is the net heat flux, which can calculate from Eq. (4). $T_{w}$ is the wall temperature and $T_{m}$ is the mean temperature, which can calculate from Eq. (5).

$\dot{q}_{\text {net }}=\dot{q}_{\text {input }}-\left(\dot{q}_{\text {rad,loss }}+\dot{q}_{\text {conv }, \text { loss }}\right)$

$T_{m}=\frac{T_{\text {in }}+T_{\text {out }}}{2}$

The heat flux generated on the stainless foil is represented by $\dot{q}_{i n}$, which is evaluated from

$\dot{q}_{\text {input }}=\frac{I V}{A}$

$\dot{q}_{\text {rad }, \text { loss }}=\sigma \varepsilon_{T L C}\left(\bar{T}_{w}^{4}-\bar{T}_{\text {surr }}^{4}\right)$

$\dot{q}_{\text {conv }, \text { loss }}=h_{c}\left(\bar{T}_{w}-\bar{T}_{\text {surr }}\right)$

where $I$ is the supplied electric current, $V$ is the measured voltage, and $A$ is the area of the heat transfer surface. $\dot{q}_{\text {rad }}$ and $\dot{q}_{c o n v}$ are the heat loss from radiation and convection from TLCs to the surrounding, respectively, $\sigma$ is the Stefan-Boltzmann constant, $\varepsilon_{T L C}$ is the emissivity coefficient for the TLC sheet which was $0.9, T_{\text {in }}$ and $T_{\text {out }}$ are respective the inlet and outlet temperature of the air, $T_{\text {out }}$ is the room temperature, $h_{c}$ is the natural heat transfer coefficient that was arranged for a vertical plate $[19,20]$. Finally, the local Nusselt number $(\mathrm{Nu})$ can determine from

$N u=\frac{h D_{j}}{\mathrm{k}}$

where $\mathrm{k}$ is the thermal conductivity at the mean air temperature. The uncertainty values due to measurements of this experiment were less than $4.2 \%$ for the Reynolds number and $3.8 \%$ for the Nusselt number evaluated according to Moffat [21].

\section{Results and Discussion}

\subsection{Contour and Local Nusselt Number}

Comparison of Nusselt number contours on impingement surface for leading $(L S)$ and trailing sides (TS) at different rotation number at $R o=0.0,0.0049,0.0099$ is shown in Figure 7 for case of jetto-impingement surface distance $L / D_{j}=2$ and $\operatorname{Re}=6,700$. The results show that the Nusselt number distributions for all Ro cases decrease from $2^{\text {nd }}$ jet to $11^{\text {th }}$ jet, while the local Nusselt number in the case of $R o=0.0049$ and 0.0099 significantly decreases when compared to the case of stationary at $R o=0.0$.

Due to the effect of crossflow, the local Nusselt number for $4^{\text {th }}$ jet to $11^{\text {th }}$ jet decrease as going downstream and the peak of local Nusselt number shifted to downstream more for the jet at downstream. This causes by the impinged jet flow along the channel and becomes crossflow to the impinging jet downstream. The jet flow was deflected by the crossflow before impinging on the 
surface. As going downstream, the effect of crossflow become more robust, and the jet flow was deflected and interacted with crossflow before impinging on the surface. The momentum of jet impinged on surface reduced and resulted in a lower Nusselt number in the downstream region.

It is also found that the impinging jet near the outlet of the flow channel ( $9^{\text {th }}$ jet to $11^{\text {th }}$ jet) provides a high local Nusselt number in the impingement region again. This may be due to the crossflow interacted with the jet flow and promoted the turbulent intensity of jet before impinging, which was also explained noticeably for the case of low jet-to-impingement surface distance in previous similar research [16]. The effect of rotations also increases the heat transfer significantly in the trailing surface (TS) when compared with the leading surface (LS) due to the Coriolis and centrifugal acceleration effects. However, those sides still show lower than in the case of stationary (ST) for large areas.

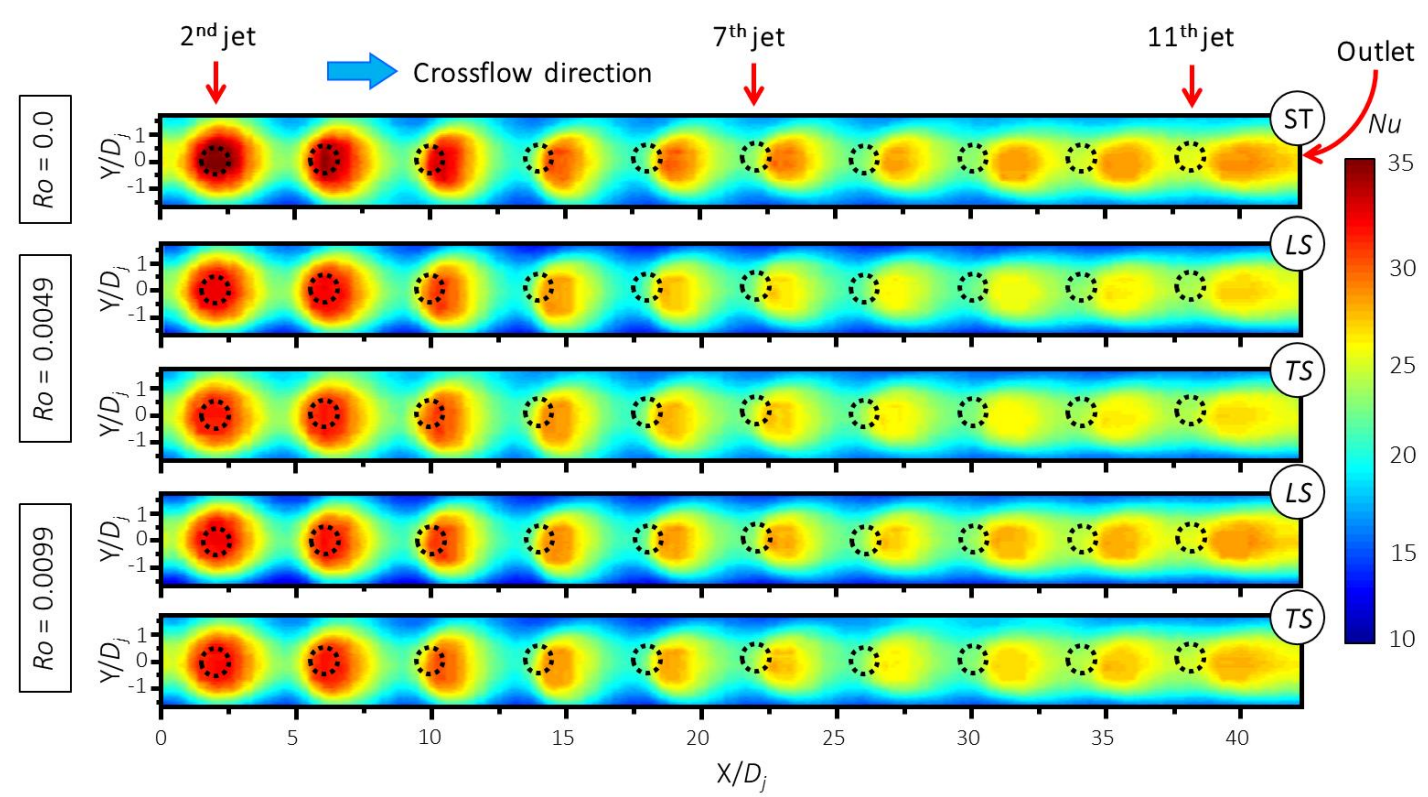

Fig. 7. The Nusselt number distributions on measurement surface of impinging jet both leading (LS) and trailing sides (TS) at $R o=0.0,0.0049,0.0099, L / D_{j}=2$ and $R e=6,700$

Figure 8 shows the local Nusselt number ratio $\left(N u_{R o} / N u_{s}\right)$ along the centre of the channel (along $\mathrm{X}$-axis and $\left.\mathrm{Y} / D_{j}=0\right)$, here $N u_{s}$ is the local Nusselt number for a stationary case. This figure indicates the effect of rotation on the local Nusselt number. It is found that the local Nusselt number ratio gradually decreases as going downstream due to the crossflow effect. The local heat transfer on the leading side $(L S)$ in the region of $0 \leq X / D_{j} \leq 20$ is higher than on the trailing side (TS) while heat transfer on the leading side ( $L S$ ) in the region of $20 \leq X / D_{j} \leq 40$ shows lowest when compared to on the trailing side (TS). This is due to the Coriolis acceleration effect. The Coriolis force affected strongly in the region of $30 \leq X / D_{j} \leq 40$. It destroys the thermal boundary layer on the $T S$ better than on the $L S$. 


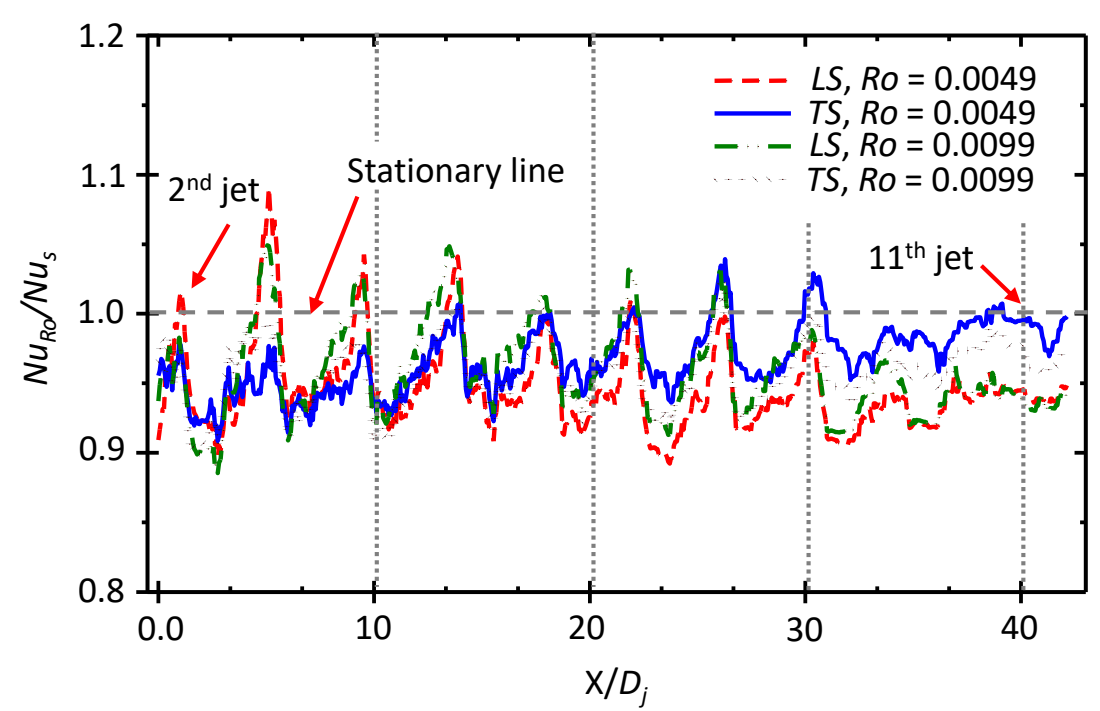

Fig. 8. The local Nusselt number ratio $\left(N u_{R o} / N u_{s}\right)$ on the impingement surface along $\mathrm{X}$-axis $\left(\mathrm{Y} / D_{j}=0\right)$ at $\mathrm{Re}=6,700$

\subsection{Average Nusselt Number}

Figure 9 demonstrates the average Nusselt number ratios $\left(\overline{N u}_{R o} \overline{N u}_{s}\right)$ on measurement surface along $\mathrm{X}$-axis at $\operatorname{Re}=6,700$. The average Nusselt number was calculated along the $\mathrm{X}$-axis $\left(\mathrm{Y} / D_{j}=0\right)$ of the heat transfer surface. The results show that all cases of rotations give the $\overline{N u}_{R o} \overline{N u}_{s}$ lower than a stationary case. The $\overline{N u}_{R o} / \overline{N u}_{s}$ on the leading side (LS) at $R o=0.0049$ ( $\mathrm{N}=200 \mathrm{rpm}$ ) is the lowest of about $5.51 \%$ when compared with stationary. Subsequently, less than $3.41 \%, 4.47 \%$, and $4.39 \%$ of the trailing side (TS) at $R o=0.0049$, the $L S$ and $T S$ at $R o=0.0099(\mathrm{~N}=400 \mathrm{rpm})$, respectively. For $R o$ $=0.0049$, above $2.17 \%$ of the $\overline{N u}_{R o} / \overline{N u}_{s}$ on the $T S$ is higher than on the $L S$ while the $\overline{N u}_{R o} / \overline{N u}_{s}$ on the $T S$ for $R o=0.0099$ differs from the $L S$ of about $0.08 \%$.

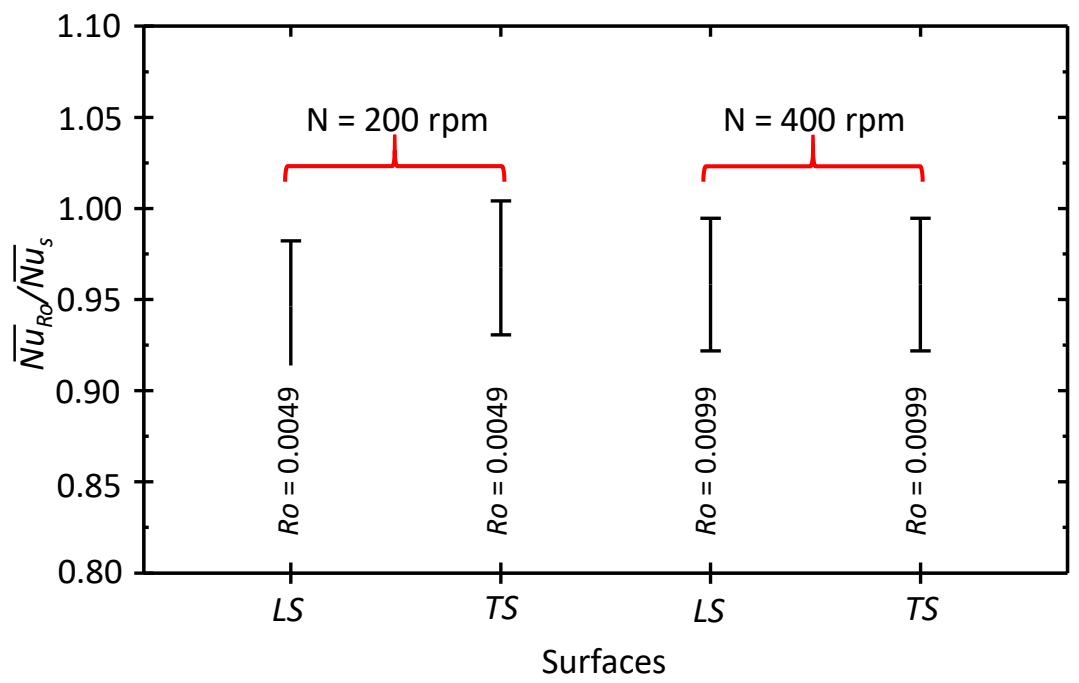

Fig. 9. The average Nusselt number ratio $\left(\overline{N u}_{R o} / \overline{N u}_{s}\right)$ on measurement surface along $\mathrm{X}$-axis $\left(\mathrm{Y} / D_{j}=0\right)$ at $\mathrm{Re}=6,700$ 


\section{Conclusions}

The primary purpose of this research was to study the effect of rotation number on heat transfer characteristics of a row of impinging jets from circular orifices in a confined channel. All experimental results can be summarized as follow

i. Effect of crossflow and Coriolis/centrifugal forces leads to the heat transfer coefficient due to the rotational effect increases significantly near the outlet of the channel when compared with the stationary channel, while heat transfer near the $2^{\text {nd }}$ jet area gives the highest heat transfer.

ii. The local Nusselt number on the leading side $(L S)$ at $0 \leq X / D_{j} \leq 20$ is higher than on the trailing side (TS) while heat transfer on the $L S$ at $20 \leq X / D_{j} \leq 40$ is the lowest when compared to on the $T S$. This is due to the Coriolis acceleration effect.

iii. The average Nusselt number ratios $\left(\overline{N u}_{R o} / \overline{N u}_{s}\right)$ on the $T S$ at $R o=0.0049$ are about $2.17 \%$ higher than on the $L S$ while the $\overline{N u}_{R O} / \overline{N u}_{S}$ on the $T S$ for $R o=0.0099$ differs from the $L S$ of about $0.08 \%$.

\section{Acknowledgment}

This research was funded by a grant from the Department of Mechanical Engineering, Faculty of Engineering, Prince of Songkla University, Thailand.

\section{References}

[1] Ligrani, Phillip M., and Gazi I. Mahmood. "Variable property Nusselt numbers in a channel with pin fins." Journal of Thermophysics and Heat Transfer 17, no. 1 (2003): 103-111. https://doi.org/10.2514/2.6740

[2] Siddique, Waseem, Naveed Ahmed Khan, and Inamul Haq. "Analysis of numerical results for two-pass trapezoidal channel with different cooling configurations of trailing edge: The effect of dimples." Applied Thermal Engineering 89 (2015): 763-771. https://doi.org/10.1016/j.applthermaleng.2015.06.067

[3] Chen, Yu, Y. T. Chew, and B. C. Khoo. "Heat transfer and flow structure in turbulent channel flow over protrusions." International Journal of Heat and Mass Transfer $66 \quad$ (2013): $177-191$. https://doi.org/10.1016/i.ijheatmasstransfer.2013.07.014

[4] Wang, Chen, Zhongliang Liu, Guangmeng Zhang, and Ming Zhang. "Experimental investigations of flat plate heat pipes with interlaced narrow grooves or channels as capillary structure." Experimental Thermal and Fluid Science 48 (2013): 222-229. https://doi.org/10.1016/i.expthermflusci.2013.03.004

[5] Kreith, Frank, and David Margolis. "Heat transfer and friction in turbulent vortex flow." Applied Scientific Research, Section A 8, no. 1 (1959): 457-473. https://doi.org/10.1007/BF00411769

[6] Han, Je-Chin, and Hamn-Ching Chen. "Turbine blade internal cooling passages with rib turbulators." Journal of Propulsion and Power 22, no. 2 (2006): 226-248. https://doi.org/10.2514/1.12793

[7] Chupp, Raymond E., Harold E. Helms, Peter W. McFadden, and Tony R. Brown. "Evaluation of internal heat-transfer coefficients for impingement-cooled turbine airfoils." Journal of Aircraft 6, no. 3 (1969): $203-208$. https://doi.org/10.2514/3.44036

[8] Kaewchoothong, Natthaporn, Kittinan Maliwan, Kenichiro Takeishi, and Chayut Nuntadusit. "Effect of rotation number on flow and heat transfer characteristics in serpentine passage with ribbed walls." Journal of Mechanical Science and Technology 32, no. 9 (2018): 4461-4471. https://doi.org/10.1007/s12206-018-0843-z

[9] Kaewchoothong, Natthaporn, Makatar Wae-Hayee, Passakorn Vessakosol, Banyat Niyomwas, and Chayut Nuntadusit. "Flow and heat transfer characteristics of impinging jet from expansion pipe nozzle with air entrainment holes." In Advanced Materials Research, vol. 931, pp. 1213-1217. Trans Tech Publications Ltd, 2014. https://doi.org/10.4028/www.scientific.net/AMR.931-932.1213

[10] Nuntadusit, C., M. Wae-hayee, and N. Kaewchoothong. "Heat transfer enhancement on a surface of impinging jet by increasing entrainment using air-augmented duct." International Journal of Heat and Mass Transfer 127 (2018): 751-767. https://doi.org/10.1016/j.ijheatmasstransfer.2018.06.130

[11] San, Jung-Yang, and Mao-De Lai. "Optimum jet-to-jet spacing of heat transfer for staggered arrays of impinging air jets." International Journal of Heat and Mass Transfer 44, no. 21 (2001): 3997-4007. https://doi.org/10.1016/S0017-9310(01)00043-6 
[12] Esposito, Eric lan. "Jet impingement cooling configurations for gas turbine combustion." PhD diss., Louisiana State University, 2006.

[13] Geers, L. F. G., M. J. Tummers, T. J. Bueninck, and K. Hanjalić. "Heat transfer correlation for hexagonal and in-line arrays of impinging jets." International Journal of Heat and Mass Transfer 51, no. $21-22$ (2008): 5389-5399. https://doi.org/10.1016/j.ijheatmasstransfer.2008.01.035

[14] Elston, Cassius A., and Lesley M. Wright. "Leading Edge Jet Impingement Under High Rotation Numbers." Journal of Thermal Science and Engineering Applications 9, no. 2 (2017): 021010. https://doi.org/10.1115/1.4035892

[15] Parsons, J. A., J. C. Han, and C. P. Lee. "Rotation effect on jet impingement heat transfer in smooth rectangular channels with four heated walls and radially outward crossflow." Journal of Turbomachinery 120, no. 1 (1998): 79 85.https://doi.org/10.1115/1.2841392

[16] Lamont, Justin A., Srinath V. Ekkad, and Mary Anne Alvin. "Effects of rotation on heat transfer for a single row jet impingement array with crossflow." Journal of Heat Transfer 134, no. 8 (2012). https://doi.org/10.1115/1.4006167

[17] Yang, Li, Kartikeya Tyagi, Srinath Ekkad, and Jing Ren. "Influence of Rotation on Heat Transfer in a Two-Pass Channel With Impingement Under High Reynolds Number." In ASME Turbo Expo 2015: Turbine Technical Conference and Exposition. American Society of Mechanical Engineers Digital Collection. https://doi.org/10.1115/GT2015-42871

[18] Chang, Shyy Woei, and Kuo-Ching Yu. "Thermal performance of radially rotating trapezoidal channel with impinging jet-row." International Journal of Heat and Mass Transfer $136 \quad$ (2019): 246-264. https://doi.org/10.1016/i.ijheatmasstransfer.2019.02.098

[19] Kaewchoothong, Natthaporn, Kittinan Maliwan, Kenichiro Takeishi, and Chayut Nuntadusit. "Effect of inclined ribs on heat transfer coefficient in stationary square channel." Theoretical and Applied Mechanics Letters 7, no. 6 (2017): 344-350. https://doi.org/10.1016/i.taml.2017.09.013

[20] Kaewchoothong, Natthaporn, Pathomporn Narato, and Chayut Nuntadusit. "Experimental investigation of the heat transfer characteristics and thermal performance inside a ribbed serpentine channel during rotational effects." $\begin{array}{llllll}\text { Experimental Thermal and } & 111 & \text { (2020): } & 109973 .\end{array}$ https://doi.org/10.1016/i.expthermflusci.2019.109973

[21] Moffat, Robert J. "Describing the uncertainties in experimental results." Experimental Thermal and Fluid Science 1, no. 1 (1988): 3-17. https://doi.org/10.1016/0894-1777(88)90043-X 